Research Article

\title{
Drug utilization pattern of fixed drug combination of antipyretic and analgesic in paediatrics department of Gauhati medical college and hospital, Guwahati, Assam, India
}

\author{
Binita Singha $^{1} *$, Syed Adam Mousum ${ }^{1}$, Mangala Lahkar ${ }^{1}$, Ajoy Borah ${ }^{2}$
}

${ }^{1}$ Department of Pharmacology, Gauhati Medical College, Guwahati-32, Assam, India, India,

${ }^{2}$ Department of Pharmacology, Jorhat Medical College, Jorhat 785001, Assam, India

Received: 16 July 2016 Accepted: 13 August 2016

*Correspondence to:

Dr. Binita Singha,

Email: binitasingha2012@ gmail.com.

Copyright: () the author(s), publisher and licensee Medip Academy. This is an openaccess article distributed under the terms of the Creative Commons Attribution NonCommercial License, which permits unrestricted noncommercial use, distribution, and reproduction in any medium, provided the original work is properly cited.

\begin{abstract}
Background: Fever and pain are the most common symptoms prompting patients to seek medical attention. This study was planned to study the drug utilization pattern of fixed drug combination of antipyretic and analgesic compared to paracetamol in paediatrics department of Gauhati Medical College and Hospital.

Methods: It was a prescription based cross-sectional study where Prescriptions with fixed dose combination of antipyretic and analgesic and prescriptions with paracetamol were observed. Demographic characteristics such as age, sex and indications were also recorded. The data were analysed for the utilization pattern of antipyretic and analgesic combination and compared with prescriptions with paracetamol alone without any other analgesic combination.

Results: Out of 266 prescriptions screened 110 were prescribed with fixed dose antipyretic- analgesic combination while 156 were prescribed with paracetamol alone. The antipyretic - analgesic combination was composed of paracetamol and ibuprofen. This combination was prescribed in most of the post-operative cases and in cases with pain for various causes. Fever was the most common condition where only paracetamol and no other analgesic were prescribed. Percentage of combination prescribed was highest in children between $10-14$ years of age and least in infants.

Conclusions: This study shows the increase utilization of antipyretic-analgesic combinations in various conditions and the preference of fixed dose combination over paracetamol increases with increase in age of the paediatric patients.
\end{abstract}

Keywords: Ibuprofen, Paracetamol, Prescription study, Children

\section{INTRODUCTION}

Fever and pain are the most common symptoms prompting patients to seek medical attention. Antipyretics are drugs that lowers raised body temperature. ${ }^{1}$ The role of antipyretics in children is sceptical as most children tolerate low grade fever (less than $38.5^{\circ} \mathrm{C}$ ) well. ${ }^{2}$ Most common antipyretic used in paediatrics is paracetamol. ${ }^{3}$ Ibuprofen has equivalent antipyretic efficacy to Paracetamol when used at recommended doses, but it is unclear whether ibuprofen is equally effective in relieving important clinical outcomes like child's discomfort and symptoms. It is also unclear whether Ibuprofen has any safety advantage. ${ }^{4}$ Antipyretic analgesic combinations are used commonly in paediatrics in cases of fever with pain and other conditions. The most common combination is ibuprofen and paracetamol. Both paracetamol and ibuprofen fall under non-steroidal antiinflammatory group of drugs (NSAIDs). NSAIDs are one of the most common causes of adverse drug reactions (ADRs) reported to drug regulatory agencies as well as encountered in many clinical and epidemiological studies. $^{5}$ The common adverse effects are gastric irritation or erosions, nausea and vomiting, headache, 
bleeding etc. ${ }^{6}$ The use of ibuprofen and paracetamol in the paediatric population has been a topic of research for more than 30 years. The efficacy and safety of this combination have not been well evaluated and the physiological effects of each agent may potentiate the risk of toxicity. ${ }^{7,8}$ The American Academy of paediatrics and the National Institute for Health and Clinical Excellence have advised against routinely using paracetamol and ibuprofen simultaneously. ${ }^{8}$ The frequency and the indications for such combinations are not specific. The present study has been undertaken to look for such indications and how frequently fixed dose combinations of antipyretic and analgesic are used over paracetamol only prescriptions in the paediatric populations.

\section{METHODS}

The present study was conducted in the Department of Paediatrics, Gauhati Medical College, Guwahati. The protocol was approved by the Institutional Ethics Committee of Gauhati Medical College and Hospital, Guwahati bearing approval no. MC/2/2015/83.

The study was conducted in the paediatrics (inpatient and outpatient) department of Gauhati Medical College and Hospital.

It was a prescription based cross-sectional study. The study was conducted for duration of 6 months (June 2015 to Nov 2015).

\section{Inclusion criteria}

- Paediatric patients of all age groups

- Paediatric patients of both sexes

- Paediatric patients prescribed with fixed dose combination of antipyretic and analgesic

- Paediatrics patients prescribed with paracetamol.

\section{Exclusion criteria}

- Paediatric patients not prescribed with fixed dose combination of antipyretic and analgesic

- Paediatric patient not prescribed with paracetamol.

\section{Method of data collection}

The samples were collected from the indoor and outpatient department of paediatrics, Gauhati Medical College and Hospital regularly for a period of six months from June 2015 to November 2015. The indoor samples were collected every Monday, Wednesday and Friday while the outdoor samples were collected every Tuesday, Thursday and Saturday. Prescriptions with fixed dose combination of antipyretic and analgesic and prescriptions with paracetamol were observed. Demographic characteristics such as age, sex and indications were also recorded. The data were analysed for the utilization pattern of antipyretic and analgesic combination and compared with prescriptions with paracetamol used alone without any other analgesic in combination. The various conditions for which antipyretic-analgesic combinations were given preference over paracetamol were also observed.

\section{RESULTS}

The results of the study have been expressed in Tables 1,2 and Figures 1, 2, 3, 4, 5, 6.

Table 1: Indications and number of prescriptions of antipyretic-analgesic combination and paracetamol.

\begin{tabular}{|c|c|c|c|}
\hline Drug & Indicatio & $\begin{array}{l}\text { No. of } \\
\text { prescription }\end{array}$ & Percentage \\
\hline \multirow{7}{*}{ Paracetamol } & Fever & 134 & $50.4 \%$ \\
\hline & Pain & & \\
\hline & \multicolumn{3}{|c|}{ Trauma, Abcess, Cysts, Ulcer } \\
\hline & & 12 & $4.5 \%$ \\
\hline & \multicolumn{3}{|c|}{ Post-operative } \\
\hline & & 10 & $3.76 \%$ \\
\hline & Total & 156 & $58.65 \%$ \\
\hline \multirow{5}{*}{ Combination } & Pain & & \\
\hline & \multicolumn{3}{|c|}{$\begin{array}{l}\text { Trauma, Abcess, Inflammation after } \\
\text { vaccine injection, Lymphadenitis, } \\
\text { Insect bite, Cysts, Folliculitis }\end{array}$} \\
\hline & & 66 & $24.8 \%$ \\
\hline & $\begin{array}{l}\text { Post- } \\
\text { operative }\end{array}$ & 44 & $16.5 \%$ \\
\hline & Total & 110 & $41.35 \%$ \\
\hline
\end{tabular}

The antipyretic- analgesic combination was composed of paracetamol and ibuprofen. Paracetamol and ibuprofen combination was prescribed in most of the post-operative cases and in various painful conditions like trauma, painful cysts and other inflammatory conditions (Table 1).

Fever was the most common condition where only paracetamol and no other analgesic were prescribed. A total of $50.4 \%$ of all prescriptions was analysed were prescribed paracetamol (Table 1, Figure 1).

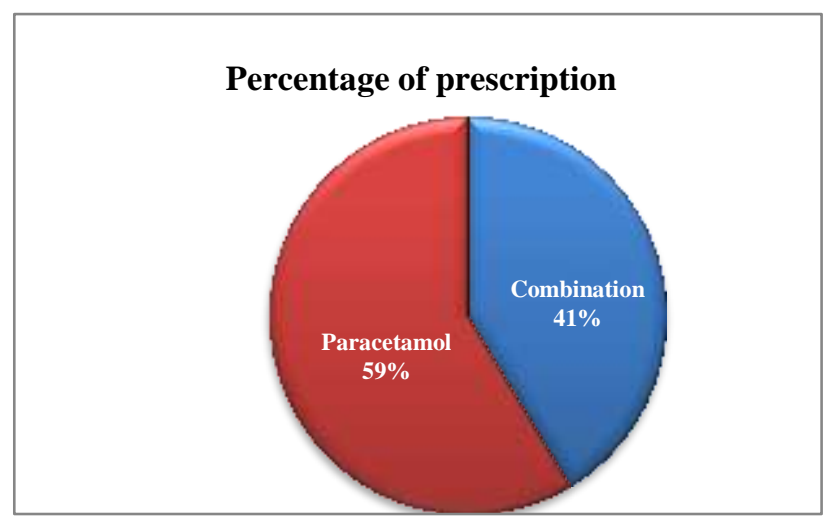

Figure 1: Percentage of prescriptions of antipyreticanalgesic combination and paracetamol. 


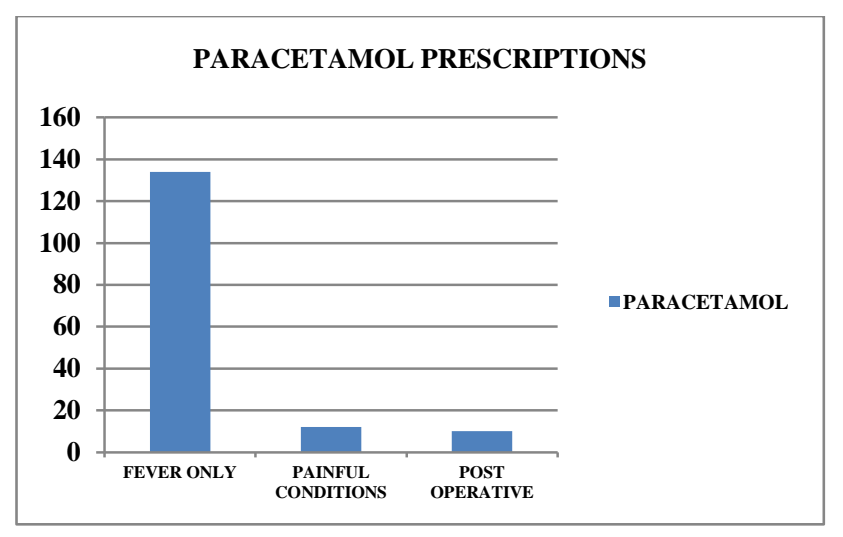

Figure 2: Number and indications of paracetamol prescriptions.

Out of 266 prescriptions screened, 110 were prescribed with fixed dose antipyretic- analgesic combination while 156 were prescribed with paracetamol alone as antipyretic or analgesic or both (Table 1, Figure 1).

Paracetamol only was also prescribed in some of the postoperative and other painful conditions but the frequency was very low (Table 1).

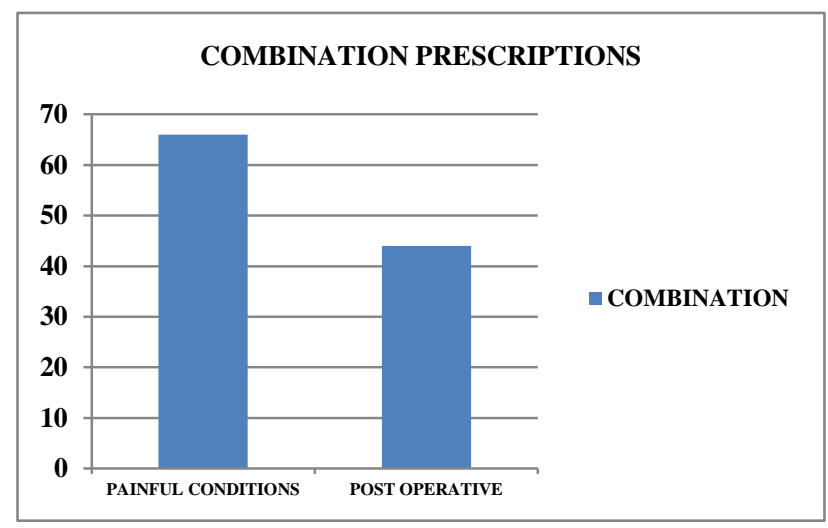

Figure 3: Number and indications of combination prescriptions.

Majority of the paracetamol only prescriptions were seen in cases of fever (Figure 2).

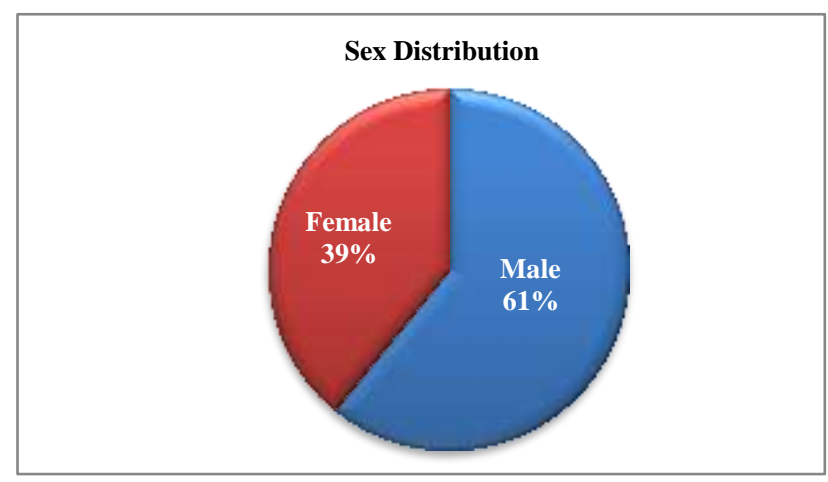

Figure 4: Sex distribution.
162 of the prescriptions analysed were of male paediatric patients, while 104 were female (Figure 4).

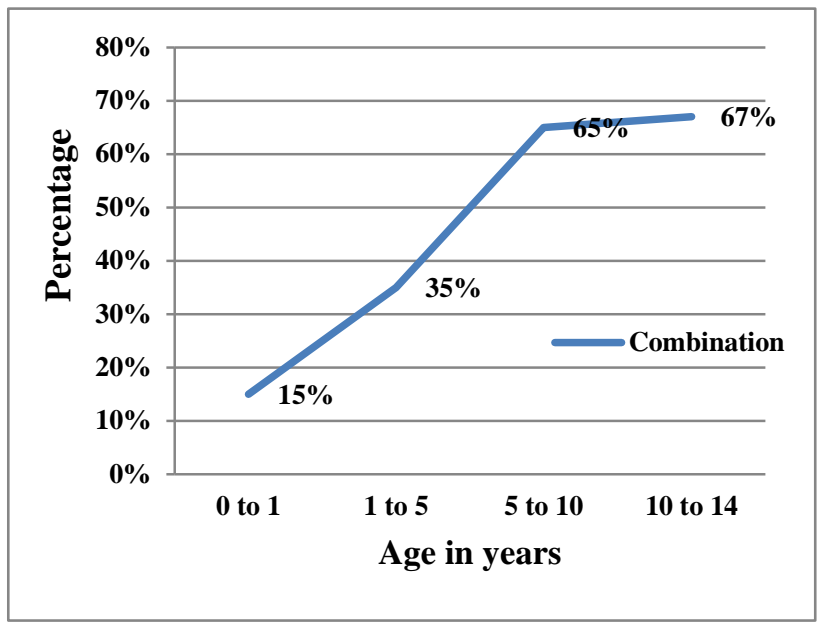

Figure 5: Percentage of antipyretic - analgesic combination prescribed in different age groups.

Percentage of combination prescribed was highest $(67 \%)$ in children between 10 - 14 years of age and least (15\%) in infants (Table 2, Figure 5).

Table 2: Number of antipyretic- analgesic combination and paracetamol prescribed in various age groups and their percentage in that age group.

\begin{tabular}{|llll|}
\hline $\begin{array}{l}\text { Age } \\
\text { group } \\
\text { (In years) }\end{array}$ & $\begin{array}{l}\text { Total } \\
\text { prescription }\end{array}$ & $\begin{array}{l}\text { Combination } \\
\text { prescribed }\end{array}$ & $\begin{array}{l}\text { Paracetamol } \\
\text { prescribed }\end{array}$ \\
\hline $0-1$ & 66 & $10(15 \%)$ & $56(85 \%)$ \\
\hline $1-5$ & 102 & $36(35.3 \%)$ & $66(64.7 \%)$ \\
\hline $5-10$ & 68 & $44(64.7 \%)$ & $24(35.3 \%)$ \\
\hline $10-14$ & 30 & $20(66.7 \%)$ & $10(33.3 \%)$ \\
\hline
\end{tabular}

Highest number of paracetamol prescriptions was seen in infants $(85 \%)$ and least $(33 \%)$ in children between $10-14$ years of age (Table 2, Figure 6).

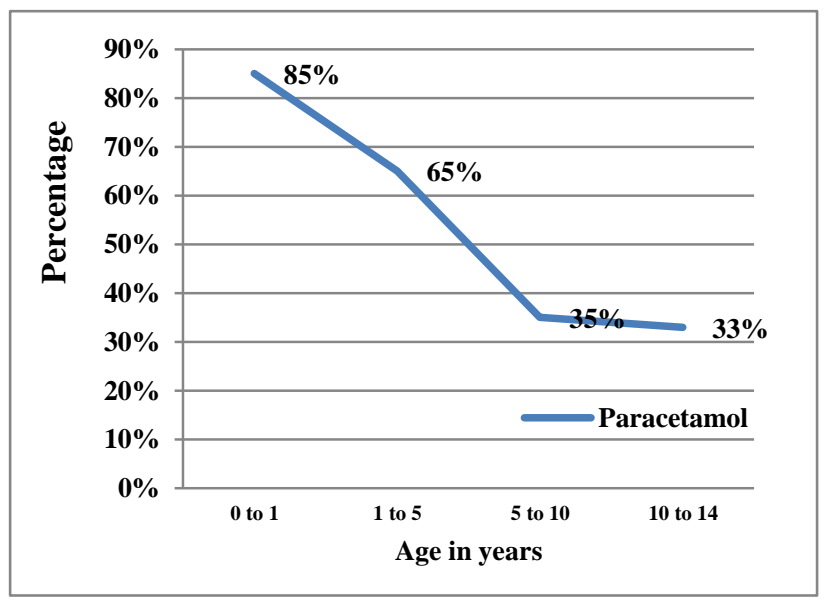

Figure 6: Percentage of paracetamol prescribed in various age groups 


\section{DISCUSSION}

For a developing country like India, a national drug policy is needed to rationalize drug use. To achieve this, it is very important to determine drug use patterns and monitor drug use profiles over time. Previous data regarding the utilization of analgesic combinations in India is largely unknown. ${ }^{9}$ Paracetamol has antipyretic and analgesic effect but has negligible anti-inflammatory actions. ${ }^{10}$ Oral ibuprofen at lower doses has analgesic activity and at higher doses shows anti-inflammatory efficacy. Long term use of ibuprofen is associated with increased adverse effects. It has been reported that combining paracetamol with ibuprofen does not affect the analgesic efficacy of ibuprofen but only increases the risk of toxicity. ${ }^{10}$ In practice however, paracetamol and ibuprofen in combinations or in alternating doses has gained popularity. This practice cannot be routinely recommended in children with such paucity of evidence to support the safety or efficacy of this combination. Paracetamol and ibuprofen have similar mechanisms of action, which theoretically increases the risk of renal and hepatic toxicity. Although such cases have not been demonstrated in large clinical trials, there are individual case reports of reversible renal damage occurring in children being given these drugs in combination. ${ }^{11}$ There is some evidence that paracetamol - ibuprofen combination more effectively lowers body temperature than each one of them alone, but evidence of the combination showing superior analgesic activity than each of them alone is lacking. ${ }^{12}$ However, Ong et al in a systematic review have reported that paracetamolibuprofen combination and paracetamol combined with other NSAIDs (non-steroidal anti-inflammatory drugs) provide better analgesia in acute postoperative pain. The human studies reviewed by Ong et al consisted of studies in children comparing paracetamol and paracetamolibuprofen combination. ${ }^{13}$ Paracetamol has been found to reduce the antibody response to vaccinations, because of which it is no longer recommended to routinely administer paracetamol before or after an immunization to reduce the likelihood of fever. ${ }^{14}$ Interestingly, Donati et al reported 19 cases of ibuprofen induced hypothermia in children in Italy. ${ }^{15}$

In this study it is seen that paracetamol is used in almost all the cases of fever as well as in various painful conditions and its combination with ibuprofen is invariably used in most of the postoperative cases and other painful conditions where ibuprofen or paracetamol alone could have given the same benefit as the combination. Paediatric patients are categorized as special population while treating and should be handled cautiously. Such combination would only increase the adverse effects as well as the expense load to the family. It is also seen that antipyretic - analgesic combination was less prescribed in infants and younger age groups and its prescription increases with increase in the age of the patients, being highest in the older age group (10-15 years). Fever was the only indication for which paracetamol was prescribed in this group (10 - 15 years). All painful conditions were prescribed with combinations only.

\section{ACKNOWLEDGEMENTS}

Authors would like to thank to Prof. K.C. Saikia, Principal-cum-Chief Superintendent, Gauhati Medical College and Hospital, for being kind enough to allow us to carry out this study and for providing the necessary infrastructure to complete this work. We would like to express our sincere gratitude towards Prof. (Mrs.) Mangala Lahkar, Professor and Head, Department of Pharmacology, GMCH for guiding us throughout, with her valuable suggestions. We sincerely acknowledge our co-PGT's, our seniors and juniors, especially to, Dr. Atifa Ahmed, Dr. Bidyut Banerjee, Dr. Chimi Handique, Dr. Karishma Adhikari for their sincere co-operation and help and providing me with the zeal and enthusiasm during the course of our study.

\section{Funding: No funding sources}

Conflict of interest: None declared

Ethical approval: Approved by IEC, Gauhati Medical College and Hospital (approval no. MC/2/2015/83)

\section{REFERENCES}

1. Tripathi KD. Essentials of medical pharmacology. $7^{\text {th }}$ edition, Jaypee Brothers Medical Publishers (P) Ltd; 2013:193.

2. Knoebel EE, Narang AS, Ey IL. Fever: to treat or not to treat. Clin Pediatr (Phila). 2002;41:9-16.

3. Ghai OP, Paul VK, Bagga A. Ghai essential pediatrics. $7^{\text {th }}$ edition, CBS Publishers and Distributers Pvt Ltd.; 2009:181-182.

4. Litalian C, Jackz-Aigrain E. Risks and benefits of non-steroidal anti-inflammatory drugs in children: a comparison with paracetamol. Pediatr Drugs. 2001;3:817-18.

5. Sullivan JE, Farrar HC. Fever and antipyretic use in children. Pediatrics. 2011;127(3):580-7.

6. Brunton LL, Chabner BA, Knollman BC. Goodman and Gilman's The Pharmacological Basis of Therapeutics, $12^{\text {th }}$ edition, McGraw-Hill; 2011:428469.

7. Pincus T, Swearingen C, Cummine P, Callahaw LP. Preference for non-steroidal anti-inflammatory drugs versus acetaminophen and concomitant use of both types of drugs in patients with osteoarthritis. J Rheumatol. 2000;27:1020-7.

8. American academy of pediatrics, committee on drugs, acetaminophen toxicity in children. Paediatrics. 2001;108:1020-4.

9. Carson SM. Alternating acetaminophen and Ibuprofen in the febrile child: examination of the evidence regarding efficacy and safety. Pediatr Nurs. 2003;29:379-82. 
10. Tripathi KD. Essentials of Medical Pharmacology. $7^{\text {th }}$ edition, Jaypee Brothers Medical Publishers (P) Ltd; 2013:209.

11. Smith C, Goldman R. Alternating acetaminophen and ibuprofen for pain in children. Can Fam Physician. 2012;58:645-7.

12. Sullivan JE, Farrar HC. Fever and antipyretic use in children. Pediatrics. 2011;127:580-7.

13. Ong C, Seymour R, Lirk P, Merry AF. Combining paracetamol (acetaminophen) with non-steroidal antiinflammatory drugs: a qualitative systematic review of analgesic efficacy for acute postoperative pain. Anesth Analg. 2010;110:1170-9.
14. Prymula R, Siegrist C, Chibek R, Zemlickova H, Vackova M, Smetana J, et al. Effect on prophylactic paracetamol administration at time of vaccination on febrile reactions and antibody responses in children: two open-label, randomized controlled trials. Lancet. 2009;374:1339-50.

15. Donati M, Monaco L, Melis M, Sottosanti L, Biagi C, Vaccheri A, et al. Ibuprofen-associated hypothermia in children: analysis of the Italian spontaneous reporting database. Eur J Clin Pharmacol, 2016. Available at http://www.ncbi.nlm.nih.gov/pubmed/27417946.

Cite this article as: Singha B, Mousum SA, Lahkar M, Borah A. Drug utilization pattern of fixed drug combination of antipyretic and analgesic in paediatrics department of Gauhati medical college and hospital, Guwahati, Assam, India. Int J Basic Clin Pharmacol 2016;5:2138-42. 